\title{
FinFET Reliability Analysis by Forward Gated-Diode Method
}

\author{
Ming Fang ${ }^{1,2}$, Jin $\mathrm{He}^{1}$,Wen $\mathrm{Wu}^{1}$, Wei Zhao ${ }^{1}$, Ruonan $\mathrm{Wang}^{2}$, Ping $\mathrm{He}^{3}$ and Lei Song ${ }^{4}$ \\ ${ }^{1}$ Peking University Shenzhen SOC Key Laboratory, PKU Shenzhen Institute, China \\ ${ }^{2}$ Shenzhen Huayue terascale chip Co., Ltd, Shenzhen, P. R. China \\ ${ }^{3}$ Shenzhen Emperor Electronic Technology Co., Ltd, Nanshan District, Shenzhen,518108, China \\ ${ }^{4}$ Shenzhen SuperD Co. Ltd, Huaqiaocheng, Nanshan District, Shenzhen 518053, China
}

\begin{abstract}
The reliability issue of the FinFET is studied in details in this paper by the forward gated-diode R-G current method. Extraction of the stress induced interface states and oxide traps of FinFET is performed from a series of the R-G current measurement and developed physics expression. As the result, the interface states can be extracted by the relationship between the net increase value of the maximum substrate current ( $\Delta$ Ipeak) and stress time; and the oxide trap can be reflected by the drift of gate voltage $(\Delta \mathrm{Vg})$ corresponding to $\Delta \mathrm{Ipeak}$.
\end{abstract}

Keywords-FinFET; R-G current; stress; interface state; oxide trap; reliability issue

\section{INTRODUCTION}

The multi-gate MOSFET is considered to be one of the most promising device architectures for scaling CMOS to the 45-nm technology node and beyond [1-4]. Improved short-channel effects (SCEs), and equivalent current drivability to planar CMOS, can be expected from these devices. The FinFET architecture has emerged as one of the most successful methods [5] for fabricating double-gate[6], triple-gate [7], and the circuits formed by FinFET also show very promising results.

However, the performance of such nano-scaled devices is seriously suffered from traps in the gate oxide and the interface between $\mathrm{Si}$ field and $\mathrm{SiO}_{2}[8]$. It has been reported that the application of forward gate-diode R-G current to analyze the stress-induced interface and oxide traps of SOI MOSFET is a very useful, simple, sensitive and flexible method.

In this paper, we presented analysis of the gate voltage-induced-traps of FinFET by using this method. First, the principle of forward gated-diode R-G current method is simple introduced. The measurement and analysis of stress induced interface states and oxide traps of FinFET. Finally, we conclude with a summary.

\section{MEASURMENT AND ANALYSIS OF STRESS INDUCED INTERFACE STATE AND OXIDE TRAP OF FINFET}

Recently, a refined forward gated-diode method has been used to characterize the interface traps and extract the bulk carrier recombination lifetime in the SOI devices by extracting recombination-generation $(\mathrm{R}-\mathrm{G})$ current,. The principle and some results has been reported in references. This method is also useful to the extraction of interface states and oxide traps of FinFET.

The total diode current is the sum of the interface R-G current, bulk R-G current and the bulk diffusion current for all biasing states

$$
I_{\text {total }}=I_{R-G(\text { sur })}+I_{R-G(\text { bulk })}+I_{\text {diffusion }}
$$

No matter the gated-diode under forward bias or reward bias, the bulk R-G current $I_{R-G(b u l k)}$ could be neglected and R-G current is the significant part of the total current. Scan the gate voltage range from negative bias to positive bias (which due to the channel under gate changes from accumulation to depletion) by keeping bias on the gate-diode constantly, changes of surface potential and carrier concentration can be observed except the diffusion. R-G current rises to a peak point first and then decreases to a constant level. The maximum R-G current $\left(\mathrm{I}_{\text {peak }}\right)$ can be determined by equation $\frac{\partial F}{\partial n}=0$, and $\mathrm{I}_{\text {peak }}$ could be expressed as

$$
\begin{gathered}
I_{\text {peak }}=\frac{1}{2} q n_{i}\left(c_{n} c_{p}\right)^{1 / 2} N_{i t} W L \exp \left(\frac{q V_{b}}{2 k T}\right) \\
C_{n}=c_{p}=10^{-8} \mathrm{~cm}^{-3} \mathrm{~s}^{-1}
\end{gathered}
$$

Therefore, a peak point of R-G current can be achieved from Equation (2).

In this section, gate-diode R-G current method has been used in FinFET to extracting and distinguishing the $\mathrm{Si} / \mathrm{SiO}_{2}$ interface states and oxide traps. The 3-D structure and layout of the FINFET we tested are shown in Figure I, which were made from the fabrication process line of the Institute of Microelectronics, Peking University.

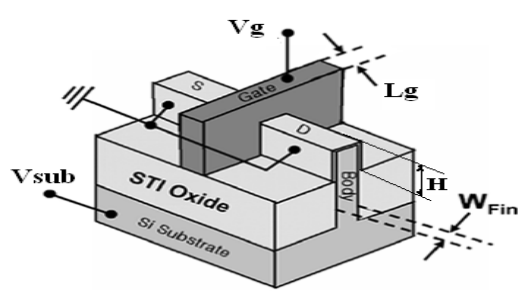

FIGURE I. 3-D STRUCTURE OF FINFET[13] 
As shown in Figure I, $\mathrm{L}_{\mathrm{g}}$ is the length of the channel, $\mathrm{W}_{\text {Fin }}$ is the width of the Si body and $\mathrm{H}$ is the height of the Si body. $\mathrm{V}_{\mathrm{g}}$ and $\mathrm{V}_{\text {sub }}$ are added to the gate and substrate, respectively. Source and drain are always grounded during the measurement.

\section{A. Analysis of Interface State and Oxide Trap}

In the measurement, the source and drain are connected to ground while applying a constant low biased voltage $V_{\mathrm{b}}$ to the body contact. As a result, the source/drain and body contact formed a forward diode. Based on the principle discussed in section II, by scanning the gate voltage from negative bias to positive bias (which due to the channel under gate changes from accumulation to depletion), the R-G current due to the interface states and oxide traps could be obtained. The gate voltage stress is set to be $3 \mathrm{~V}$ and the accumulated stress time is changed from $0 \mathrm{~s}$, through $10 \mathrm{~s}, 20 \mathrm{~s}, 50 \mathrm{~s}, 80 \mathrm{~s}, 100 \mathrm{~s}, 200 \mathrm{~s}, 500 \mathrm{~s}$, $800 \mathrm{~s}, 1000 \mathrm{~s}$, finally to $2000 \mathrm{~s}$. The R-G current characteristics of the devices were automatically recorded by a semiconductor parameter analyzer HP-4156B after stress duration.

The bias conditions we used in our measurement are exhibited as follows: (1). To prevent the forward diode formed by the drain and body from turning on, $\mathrm{V}_{\mathrm{b}}$ is set to range from $0.4 \mathrm{~V}$ to $0.5 \mathrm{~V}$ with the step of $0.01 \mathrm{~V}$. (2). $\mathrm{V}_{\mathrm{g}}$ ranges from $-0.4 \mathrm{~V}$ to $0.4 \mathrm{~V}$ and the peak value of the substrate current $\left(\mathrm{I}_{\mathrm{b}}\right)$ must be ensured in this voltage area.

Figure II. shows the relationship of $\mathrm{I}_{\mathrm{b}}$ and $\mathrm{V}_{\mathrm{g}}$ with the variation of $\mathrm{V}_{\mathrm{b}}$ without stress.

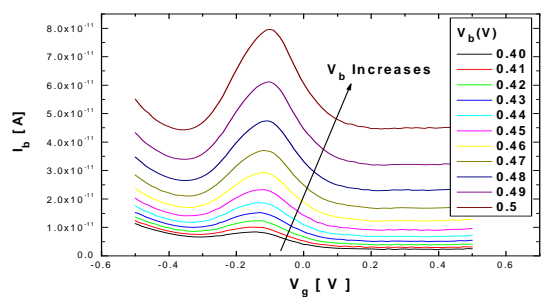

FIGURE II. $\mathrm{I}_{\mathrm{b}} \mathrm{VSS}_{\mathrm{g}}$ UNDER DIFFERENT $\mathrm{V}_{\mathrm{b}}$ WITHOUT STRESS IN FinFET

From Equation (2), we could obtain

$$
\ln I_{\text {peak }}=\ln \left[\frac{1}{2} q n_{i}\left(c_{n} c_{p}\right)^{1 / 2}\right]+\ln \left(N_{i t} W L\right)+\frac{q V_{b}}{2 k T}
$$

Figure III. shows the experiment curve of the maximum $I_{b}\left(I_{\text {peak }}\right)$ versus $V_{b}$ and fitted linearly by the equation $y=A+B x$.

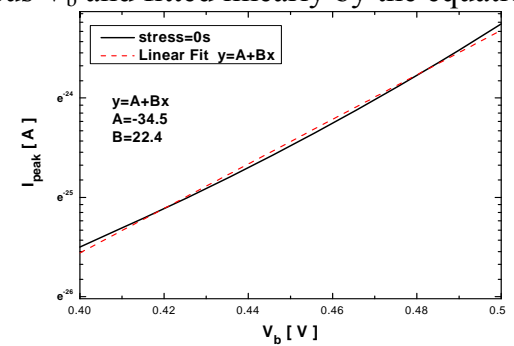

FIGURE III. THE EXPERIMENT CURVE AND THE LINEARLY FIT CURVE OF $\mathrm{I}_{\text {peak }}-\mathrm{V}_{\mathrm{b}}$, WITH FIT PARAMETERS A $=-34.5$, $\mathrm{B}=22.4$ IN FinFET
From Equation(3), $A$ and $B$ can be written as

$$
A=\ln \left[\frac{1}{2} q n_{i}\left(c_{n} c_{p}\right)^{1 / 2}\right]+\ln \left(N_{i t} W L\right), \quad B=\frac{q}{2 k T}
$$

By linear fitting, we got $\ln \left(N_{i t} W L\right)=-7.08$.

Because the performance of a FinFET is equal to a double gate MOSFET, which means that the factor WL in parameter $\mathrm{A}$ is determined by the gates at both sides of the Si film. Assuming that the $\mathrm{Si} / \mathrm{SiO}_{2}$ interface states density $N_{i t}$ is equal to the normal value about $5 \times 10^{10} \mathrm{~cm}^{-2}$. According to Equation (3), the product of $\mathrm{Si}$ body height (corresponding to the channel width) and the effective gate length (WL) is equal to $67.2 \mathrm{~nm}^{2}$.

The relationship between the substrate current $\mathrm{I}_{\mathrm{b}}$ and gate voltage $\mathrm{V}_{\mathrm{g}}$ under different stress time by keeping $\mathrm{V}_{\mathrm{b}}=0.5 \mathrm{~V}$ is shown in Figure IV. An increase of $\mathrm{I}_{\mathrm{b}}$ with increasing stress time is observed. In Figure VI, the slops of all the $I_{\text {peak }}-V_{b}$ curves are almost the same, and the value is about $q / 2 \mathrm{kT}$, which corresponds to Equation (3) very well. Meanwhile, the increase of the interface states density $N_{i t}$ with increased stress time is reflected by the increasing of the intercept of $I_{\text {peak }}-V_{b}$ curves as shown in Figure V. The differences of intercept under stresses between the fresh one implies the interface states induced by the stress. The dependence of $\Delta \mathrm{I}_{\text {peak }}$ and interface states distribution to the stress time is shown in Figure VI and Figure VII. From Figure VII we can get the relationship between net increased $\mathrm{N}_{\mathrm{it}}\left(\Delta \mathrm{N}_{\mathrm{it}}\right)$ and stress time $(t)$ is $\Delta N_{i t} \propto t^{0.39}$.

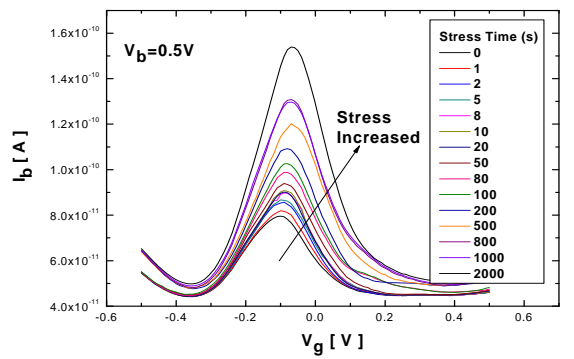

FIGURE IV. $\mathrm{I}_{\mathrm{b}}$ VERSUS $\mathrm{V}_{\mathrm{g}}$ CHARACTERISTICS UNDER DIFFERENT STRESS TIME

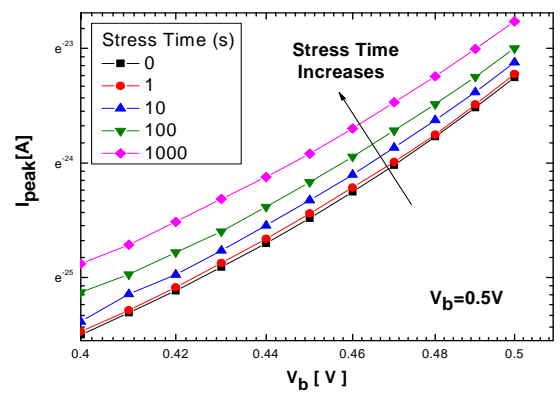

FIGURE V. $\mathrm{I}_{\text {peak }}$ VERSUS $\mathrm{V}_{\mathrm{b}}$ CHARACTERISTICS UNDER DIFFERENT STRESS TIME IN FinFET 


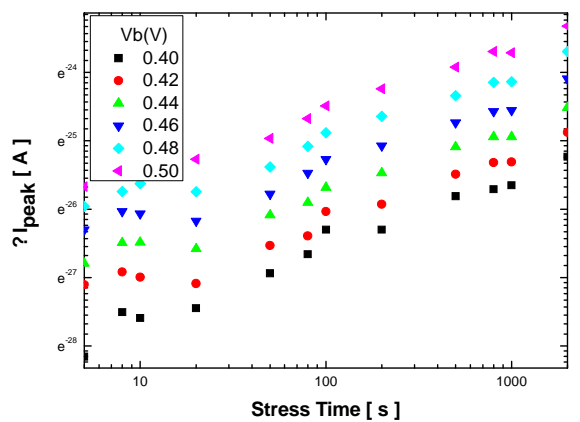

FIGURE VI. $\Delta \mathrm{I}_{\text {peak }}$ VERSUS STRESS TIME UNDER DIFFERENT $\mathrm{V}_{\mathrm{b}}$ IN FinFET

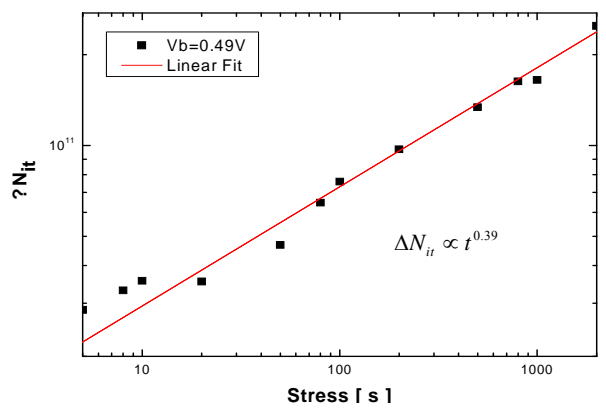

FIGURE VII. THE DEPENDENCE OF THE INTERFACE STATES DISTRIBUTION TO THE STRESS TIME IN FinFET

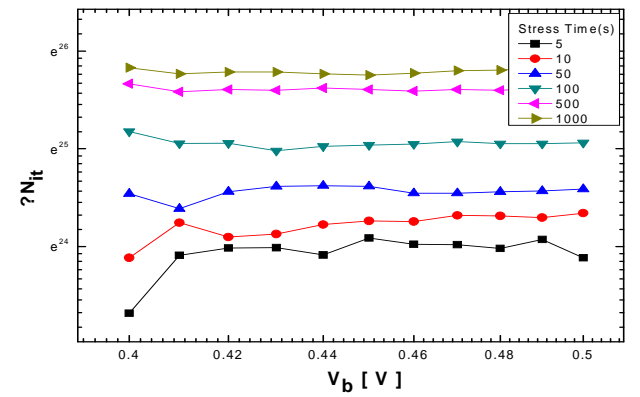

FIGURE VIII. THE GENERATION OF INTERFACE STATE VERSUS $\mathrm{V}_{\mathrm{b}}$ UNDER DIFFERENT STRESS TIME IN FinFET

Figure VIII shows the relationship between the interface state generation and $\mathrm{V}_{\mathrm{b}}$ under different stress time. We can observe that the generation of interface states increases with the stress time but almost independent of $\mathrm{V}_{\mathrm{b}}$. This phenomenon implies that the front gate interface is less affected by the increasing $\mathrm{V}_{\mathrm{b}}$. The increased $\mathrm{V}_{\mathrm{b}}$ just supply more carriers which reacted with the interface states to generate larger substrate current $\left(\mathrm{I}_{\mathrm{b}}\right)$. So under a constant stress situation, the drift of the peak value in $\mathrm{I}_{\mathrm{b}}-\mathrm{V}_{\mathrm{g}}$ characteristics with different $\mathrm{V}_{\mathrm{b}}$ (i.e. Figure II) is determined only by the charge in the oxide, so the oxide charge density under some stress could be extracted by the drift of $\mathrm{I}_{\text {peak }}$ following this equation

$$
\Delta V=C_{o x} Q_{o x}
$$

where $\Delta V$ is the difference between the $\mathrm{V}_{\mathrm{b}}$ corresponding to the drifted $\mathrm{I}_{\text {peak }}, \mathrm{C}_{\mathrm{ox}}$ is the capacitance of the gate oxide, and $\mathrm{Q}_{\mathrm{ox}}$ is charges trapped by the oxide traps.

\section{B. Hot Carrier Induced Interface State and Oxide Trap}

Hot carrier due to the high electrical field near the drain area will induce the interface states and oxide trap. In order to analyze the trap generation induced by the hot carrier effect, we add the stress to the device under the condition of $\mathrm{V}_{\mathrm{d}}=3.5 \mathrm{~V}, \mathrm{~V}_{\mathrm{g}}=1.11 \mathrm{~V}$, so that the largest substrate current $\mathrm{I}_{\mathrm{b}}$ could be observed. And the stress time ranges from 0 s, through $10 \mathrm{~s}, 20 \mathrm{~s}, 50 \mathrm{~s}, 80 \mathrm{~s}, 100 \mathrm{~s}, 200 \mathrm{~s}, 500 \mathrm{~s}, 800 \mathrm{~s}$, finally to $1000 \mathrm{~s}$. In this section, we focus our attention on the degradation of I-V characteristics to analyze the interface state and oxide trap.

Figure IX is the $\mathrm{I}_{\mathrm{b}}-\mathrm{V}_{\mathrm{g}}$ characteristic without stress. It is shown in Figure IX that $\mathrm{I}_{\mathrm{b}}$ increasing with increased $\mathrm{V}_{\mathrm{b}}$ before stress. But voltage corresponding to the peak of $\mathrm{I}_{\mathrm{b}}$ is almost steady. So we can conclusion that the increase of $V_{b}$ just supplies larger recombine current but does not generate interface states or oxide traps which induce the degradation of the sub threshold slop and threshold voltage. Figure I0 is the $\mathrm{I}_{\mathrm{b}}-\mathrm{V}_{\mathrm{g}}$ characteristic under different stress time. The increasing of $\mathrm{I}_{\mathrm{b}}$ with increased stress time can be observed. And the drift of $\mathrm{I}_{\text {peak }}$ resulted from the charges in the oxide is also observed in Figure I0.

The experiment and linear fit line of the difference between $\mathrm{I}_{\text {peak }}$ under different stress and initial $\mathrm{I}_{\text {peak } 0}$ without stress versus stress time is shown in Figure I1 and Figure I2.

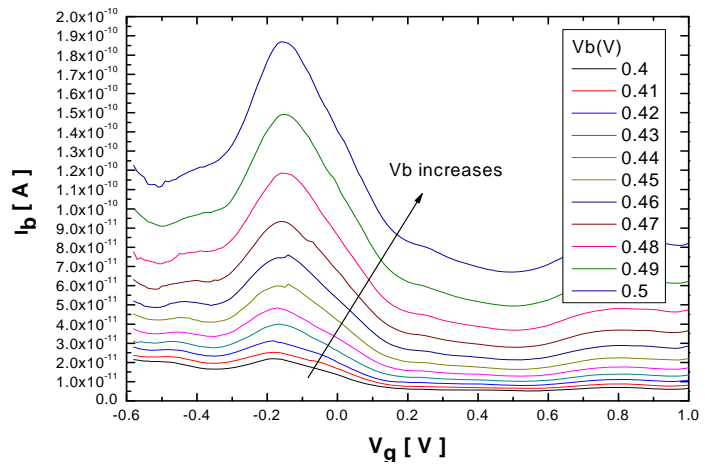

FIGURE IX. $\mathrm{I}_{\mathrm{b}}-\mathrm{V}_{\mathrm{g}}$ CHARACTERISTIC WITHOUT STRESS IN FinFET.

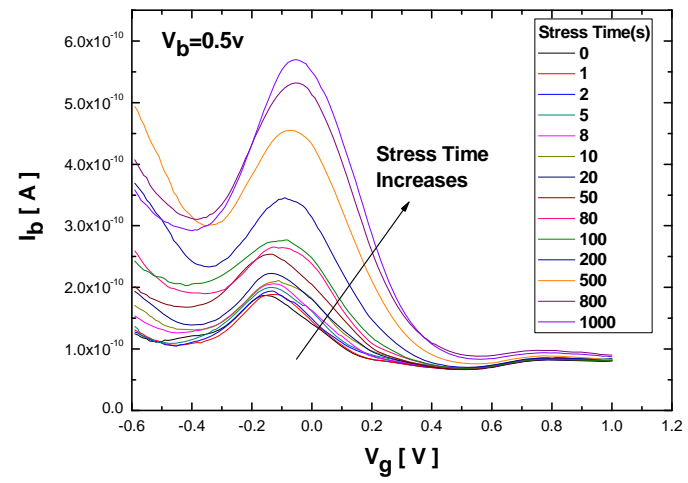

FIGURE $\mathrm{X} . \mathrm{I}_{\mathrm{b}}-\mathrm{V}_{\mathrm{g}}$ CHARACTERISTIC UNDER DIFFERENT STRESS TIME IN FinFET. 


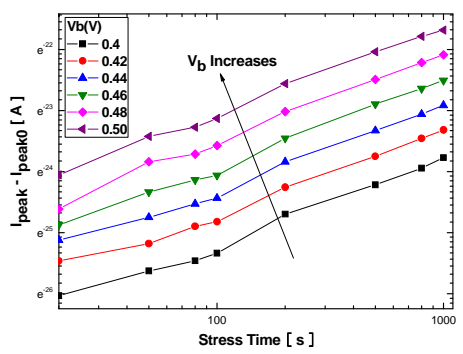

FIGURE XI. THE RELATIONSHIP BETWEEN $\triangle \mathrm{I}_{\text {peak }}$ AND STRESS TIME WITH DIFFERENT $V_{b}$ IN FinFET

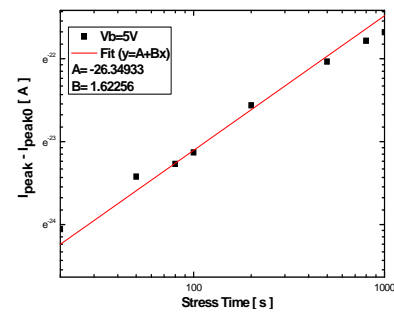

FIGURE XII. LINEAR FIT OF $\Delta \mathrm{I}_{\text {peak }}$ VERSUS STRESS TIME IN FinFET

\section{CONCLUSION}

In this paper, the $\mathrm{Si} / \mathrm{SiO}_{2}$ interface state and oxide trap of FinFET are discussed. Gate-diode R-G current method is used for extracting and distinguishing these two types of traps induced by stress. The interface states can be extracted by the relationship between the net increase value of the maximum substrate current $\left(\Delta \mathrm{I}_{\text {peak }}\right)$ and stress time; and the oxide trap can be reflected by the drift of gate voltage $\left(\Delta \mathrm{V}_{\mathrm{g}}\right)$ corresponding to $\Delta \mathrm{I}_{\text {peak }}$.

\section{ACKNOWLEDGMENTS}

This work is funded by National Natural Science Foundation of China under Grants (61574005, 61306042, 61306045, 61306132, and 61274096). This work is also supported by the Fundamental Research Project of Shenzhen Science \& Technology Foundation JCYJ 20140721163526514, and the International Collaboration Project of Shenzhen Science \& Technology Foundation (GJHZ2015031615060422, SGLH20150213140604619).

\section{REFERENCES}

[1] D. Hisamoto et al., "FinFet-A self-aligned double- gate MOSFET scalable to 20 nm," IEEE Trans. Electron Devices, vol. 47, pp. 2320-2325, Dec. 2000

[2] B. Yu, L. Chang, S. Ahmed, H. Wang, S. Bell, C.-Y. Yang, C. Tabery, C. Ho, Q. Xiang, T.-J. King, J. Bokor, C. Hu, M.-R. Lin, and D. Kyser, "FinFET scaling to $10 \mathrm{~nm}$ gate length," in IEDM Tech. Dig., 2002, pp. 251-254.

[3] E. Nowak, B. Rainey, D. Fried, J. Kedzierski, M. Ieong, W. Leipold, J. Wright, and M. Breitwisch, "A functional FinFET-DGCMOS SRAM cell," in IEDM Tech. Dig., 2002, pp. 411-414.

[4] R. Fernándeza, R. Rodríguez, M. Nafría, X. Aymerich, B. Kaczer, G. Groeseneken, FinFET and MOSFET preliminary comparison of gate oxide reliability

[5] Colinge JP, Multiple-gate SOI MOSFETs. Solid-State Electronics, 48, (2004) pp 897-905.

[6] Yang-Kyu Choi, Daewon Ha, Snow E , Bokor J, Tsu- Jae King, Reliability study of CMOS FinFETs. IEDM (2003) pp 7.6.1-7.6.3.
[7] S. H. Tang, L. Chang, N. Lindert, Y.-K. Choi, W.-C. Lee, X. Huang, V. Subramanian, J. Bokor, T.-J. King, and C. Hu, "FinFET-a quasiplanar double-gate MOSFET," in Proc. ISSCC, 2001, pp. 118-119.

[8] B. Doyle, B. Boyanov, S. Datta, M. Doczy, S. Hareland, B. Jin, J. Kavalieros, T. Linton, R. Rios, and R. Chau, "Tri-gate fully depleted CMOS transistors: Fabrication, design and layout," in Symp. VLSI Tech. Dig., 2003, pp. 133-134. 